\title{
PENYALAHGUNAAN KEKUASAAN DALAM NOVEL KORUPSI KARYA TAHAR BEN JELLOUN (KAJIAN SOSIOLOGI SASTRA)
}

\author{
Patresya Agnes Pietersz \\ Viona Sapulette \\ Falantino Eryk Latupapua
}

Email : patresyapietersz@gmail.com

\begin{abstract}
ABSTRAK: Penelitian ini bertujuan mendiskripsikan penyalahgunaan kekuasaan dalam novel Korupsi karya Tahar Ben Jelloun. Jenis penelitian ini adalah penelitian kualitatif. Data penelitian ini adalah data tulis berupa kata dan kalimat yang mengandung persoalan penyalahgunaan kekuasaan, sedangkan sumber data dalam penelitian ini adalah novel Korupsi karya Tahar Ben Jelloun. menginterpretasi data secara deskriptif menggunakan pendekatan sosiologi sastra. Hasil penelitian menunjukkan bahwa terdapat bentuk-bentuk penyalahgunaan kekuasaan dalam novel Korupsi karya Tahar Ben Jelloun yaitu: (1) penggelapan uang; (2) penyuapan; (3) korupsi; (4) pemerasan; (5) kemerosotan moral; (6) hegemoni kelas sosial; (7) marginalitas; dan (8) resistensi. Simpulan penelitian ini adalah 1) hegemoni yang terjadi pada novel ini tidak hanya sebatas dominasi kekuasaan suatu kelas sosial, tetapi juga terjadi atas dasar untuk perubahan; 2) hegemoni kekuasaan kelas sosial pada novel Korupsi adalah penindasan oleh kelas penguasa terhadap kaum subaltern; 3) hegemoni moral merupakan sikap untuk melindungi diri; 4) marginalitas dalam novel Korupsi, yaitu pendiskriminasian terhadap orang-orang miskin.
\end{abstract}

Kata kunci: korupsi, penyalahgunaan kekuasaan, sosiologi sastra 


\title{
ABUSE OF AUTHORITY IN CORRUPTION NOVELS OF LIGHT WORKS BEN JELLOUN (LITERATURE SOCIOLOGY STUDY)
}

\author{
Patresya A Pietersz \\ Viona Sapulette \\ Falantino Eryk Latupapua \\ Email : patresyapietersz@gmail.com
}

\begin{abstract}
This study aims to describe the abuse of power in Tahar Ben Jelloun's corruption novel. This type of research is qualitative research. The data of this study are written data in the form of words and sentences that contain problems of abuse of power, while the source of the data in this study is the corruption novel by Tahar Ben Jelloun. interpreting data descriptively using the sociological approach of literature. The results showed that there were forms of abuse of power in Tahar Ben Jelloun's corruption novel, namely: (1) embezzlement of money; (2) bribery; (3) corruption; (4) extortion; (5) moral decline; (6) social class hegemony; (7) marginality; and (8) resistance. The conclusions of this study are 1) the hegemony that occurs in this novel is not only limited to the dominance of the power of a social class, but also occurs on the basis of change; 2 ) social class power hegemony in the novel corruption is the oppression by the ruling class of subalterns; 3 ) moral hegemony is an attitude to protect oneself; 4) marginality in the novel corruption, namely discrimination against poor people.
\end{abstract}

Keywords: corruption, abuse of power, sociology of literature 


\section{A. PENDAHULUAN}

Sastra merupakan ungkapan dari pengalaman penciptanya, berarti bahwa sastra tidak dapat dilepaskan dari pengalaman hidup penyair, pengarangnya atau sastrawannya. Setiap genre sastra, baik itu prosa, puisi, maupun drama hadir sebagai media berbagai pengalaman sastrawan kepada pembaca. Setiap jenis sastra selalu hadir sebagai sebuah sistem lambang budaya yang merupakan hasil intelektual sastrawan dalam merespon berbagai fenomena yang hadir di sekelilingnya. Menurut Wicaksono, (2013:1\&3) karya sastra menampilkan gambaran kehidupan dan kehidupan itu sendiri adalah suatu kenyataan sosial dan sastra lahir akibat dorongan dasar manusia untuk mengungkapkan dirinya, menaruh minat terhadap masalah manusia dan kemanusiaan, menaruh minat terhadap realitas yang berlangsung sepanjang zaman.

Novel merupakan salah satu karya sastra yang diciptakan oleh pengarangnya dengan harapan dapat dinikmati, dipahami, direnungi, dan dimanfaatkan oleh pembaca. Sebuah novel biasanya menceritakan tentang kehidupan manusia dalam berinteraksi dengan lingkungan dan sesamanya. Novel adalah karya imajinatif yang mengisahkan sisi utuh atas problematika kehidupan seseorang atau beberapa orang tokoh (Kosasih, 2012:60).

Salah satu novel yang sangat menarik bagi peneliti untuk dijadikan bahan penelitian adalah novel Korupsi. Alasannya karena pengarang novel (Tahar Ben Jelloun) dikenal dengan karya-karyanya yang bernuansa dengan kritik sosial yang cerdas dan tajam, dan karena novel ini menceritakan tentang praktik-praktik korupsi yang terjadi di kalangan birokrasi di Maroko. Penyalahgunaan wewenang 
jabatan yang biasanya dilakukan para pejabat pemerintahan adalah korupsi. Korupsi merupakan salah satu dari sekian istilah yang kini telah akrab di telinga masyarakat Indonesia, hampir setiap hari media massa memberitakan berbagai kasus korupsi yang dilakukan oleh aparatur Negara baik pegawai negeri ataupun pejabat pemerintah.

Dalam penelitian ini, peneliti menggunakan jenis novel watak yang mana novel jenis ini menekankan unsur karakter atau watak pelakunya. Pengarang ingin menggambarkan sifat-sifat watak seseorang atau beberapa tokoh, sehingga seluruh kejadian atau cerita dalam novel sangat ditentukan oleh watak tokoh-tokohnya.

Studi mengenai sastra dan hegemoni dilakukan untuk mengetahui sejauh mana hubungan sastra dengan kejadian sosial yang terjadi di masanya. Melalui hegemoni kita dapat mengetahui berbagai bentuk kekuasaan yang terangkum dalam karya sastra. Sebagimana wujud kekuasaan dalam hegemoni yang dapat dilihat dari dua golongan, yaitu golongan penguasa dan yang dikuasai. Melalui nilai-nilai kekuasaan inilah, nilai sejarah yang terkandung dalam sebuah karya sastra dapat diketahui.

Fokus penelitian ini, yakni pada penyalahgunaan kekuasaan dalam Novel Korupsi karya Tahar Ben Jelloun melalui pendekatan sosiologi sastra. Agar hasil penelitian ini menjadi pokok bahasan yang detail, maka objek penelitian dititikberatkan pada ruang lingkup hegemoni kekuasaan, yang dianalisis dengan menggunakan teori hegemoni. Hegemoni adalah kajian teori keilmuan yang membahas tentang nilai-nilai kekuasaan, yang mana dalam kekuasaan tesebut terdapat pihak sebagai penguasa dan juga pihak yang dikuasai. 


\section{B. METODE PENELITIAN}

Dalam penelitian ini, peneliti menggunakan pendekatan kualitatif. Menurut Denzin dan Lincoln (dalam Moleong, 2012:5), penelitian kualitatif adalah penelitian yang menggunakan latar alamiah dengan maksud menafsirkan fenomena yang terjadi dengan melibatkan berbagai metode yang ada. Jadi, dalam penelitian ini peneliti mendeskripsikan secara alamiah data dari proses interaksi dengan objek yang diteliti yaitu novel Korupsi karya Tahar Ben Jelloun. Penelitian ini bersifat deskriptif, yaitu memberikan gambaran secara jelas tentang bagaimana korupsi dan bentuk penyalahguaan kekuasaan.

\section{PEMBAHASAN}

Penelitian ini membahas tentang bentuk-bentuk penyalahgunaan kekuasaan dalam novel Korupsi karya Tahar Ben Jelloun. Bentuk-bentuk penyalahgunaan kekuasaan yang digambarkan dalam penelitian ini adalah bentuk-bentuk perbuatan buruk yang dilakukan orang-orang terpelajar dan terpandang yang tidak boleh kita tiru. Penyimpangan nilai-nilai moral itu terjadi karena kurangnya pemahaman dan pengamalan nilai-nilai pendidikan dalam kehidupan. Berikut ini adalah hasil penelitian mengenai bentuk-bentuk penyalahgunaan kekuasaan dalam novel Korupsi karya Tahar Ben Jelloun dengan tinjauan sosiologi sastra, yakni : a) Penggelapan uang; b) Penyuapan; c) Korupsi; d) Pemerasan; e) Kemerosotan moral; f) Hegemoni kelas sosial; g) Marginalitas; h) Resistensi.

Berdasarkan hasil penelitian, maka bentuk-bentuk penyalahgunaan kekuasaan dalam novel Korupsi karya Tahar Ben Jelloun dengan tinjauan sosiologi sastra, yakni: 


\section{Penggelapan Uang}

Pada penelitian ini, peneliti dapat memaparkan kasus-kasus penggelapan uang yang terdapat dalam novel Korupsi karya Tahar Ben Jelloun dapat dilihat pada penjelasan berikut:

Sidi Larbi adalah seorang pengacara dan Murad sangat membencinya. Sidi larbi pengacara kotor yang memperkaya dirinya dari penggelapan uang hal itu dapat dilihat pada kutipan berikut:

Sidi Larbi justru sosok yang dibenci Murad. Dia seorang pengacara busuk yang memperkaya diri dengan menilep uang ganti rugi kecalakaan lalu lintas. Dia bersekongkol dengan perusahan asuransi, memberikan sebagian ganti rugi itu kepada keluarga korban, lalu sisanya dibagi dengan sejumlah agen (jelloun, 2010:23)

Sidi Larbi menganggap Murad tidak bisa menyesuaikan dirinya dengan kehidupan modern. Kehidupan modern yang dimaksud Sidi Larbi adalah memperkaya diri dengan cara memanfaatkan segala peluang yang ada, termasuk memanfaatkan uang ganti rugi korban kecelakaan, ciri khas dari kaum kapitalisme terhadap kelas sosial rendah.

\section{Penyuapan}

Pada penelitian ini, peneliti dapat memaparkan kasus-kasus penyuapan dan penyogokan yang terdapat dalam novel Korupsi karya Tahar Ben Jelloun seperti berikut:

Haji Hamid menawarkan bantuan jasa seorang hakim yang dia kenal untuk membantu Murad jika Murad ditangkap oleh polisi karena korupsi. Haji Hamid 
akan memberikan sejumlah uang untuk menutup perkara tersebut. Lihat kutipan di bawah:

Kedua orang tak mungkin dari kepolisian. Surat mereka tidak resmi. Surat itu tidak berkepala Kementerian Dalam Negeri. Itu secarik kertas putih yang ditulisi dengan tulisan tangan. Kami akan kembali lagi! Biar saja mereka datang lagi. Aku tidak takut apapun. H.H. telah mencuri puluhan juta. Dia tidak pernah diperiksa. Kepala kantor kami baru saja membeli sebuah gedung seharga dua miliar. Gajinya tak mungkin cukup untuk mencukupi pembelian itu.

Aku tidak akan dihukum untuk beberapa ribu dirham saja! Tidak.

Pokoknya anda dapat mengandalkan saya bila ada kesulitan. Tetapi hati-hati, jangan ada pengaduan. Kalau anda ditangkap, saya bisa bicara pada seseorang yang berkedudukan tinggi. Dia mengenal hakim yang tahu apa yang harus dilakukan. Bila perlu, beberapa ribu dirham akan menutup perkara (Jelloun, 2010:132-133).

Pada kutipan di atas menggambarkan bahwa hakim dan hukum di negara berkembang dapat dibeli dengan uang, yang terdapat pada kutipan Jika anda tertangkap, saya akan berbicara kepada seseorang yang berkedudukan tinggi, seorang hakim yang mengetahui apa yang harus dilakukannya... Bila perlu, beberapa ribu dirham akan menutup perkara. Dengan kata lain, seorang hakim yang melepaskan sumpah jabatannya untuk mengadili orang yang bersalah dapat disuap. Begitu juga dengan hukum yang dapat dibeli beberapa lembar uang, karena uang lebih berkuasa dibandingkan hukum. Hegemoni atau kekuasaan yang dialami oleh hakim dikarenakan rendahnya gaji seorang hakim di negara berkembang, sehingga membuat seorang penegak hukum dapat menjual moralnya demi kepentingan pribadi, yaitu mendapatkan uang dengan jumlah yang besar. 


\section{Korupsi}

Pada penelitian ini, , peneliti dapat memaparkan kasus-kasus korupsi yang terdapat dalam novel Korupsi karya Tahar Ben Jelloun seperti; para pejabat tinggi Dinas Kesehatan yang melakukan tindakan korup. Lihat kutipan di bawah:

Pada masa itu, seorang pejabat tinggi Dinas Kesehatan, yang juga seorang dokter, menyelewengkan peralatan yang dibeli pemerintah untuk rumah sakit dan mengirimnya ke klinik pribadinya. Pada masa itu pula, orang itu menahan obat-obat tertentu di perbatasan karena perusahaan Swiss-Jerman tidak mau membayar uang komisi baginya. Si penjahat ini, yang sejak itu dinonaktifkan, kini hidup dengan tenang dari hasil kliniknya dan dari bunga uangnya, padahal dia bertanggung jawab atas kematian beratus-ratus orang (Jelloun, 2010:35).

Kutipan di atas menggambarkan bahwa seorang pejabat tinggi Dinas Kesehatan yang menyelewengkan peralatan rumah sakit ke klinik pribadinya dan hasil korupsinya itu membuatnya hidup dengan tenang. Perawat tersebut menyalahgunakan wewenang dengan maksud memperkaya diri sendiri namun tanpa berpikir bahwa ia telah merugikan negara dan perekonomian negara.

\section{Pemerasan}

Selain Murad yang mengalami ketertindasan dalam keluarga dan lingkungan kerjanya, ada seorang dokter yang baru saja diangkat di rumah sakit pusat di Casablanca dan dokter itu lebih naif daripada Murad. Seorang kepala perawat yang lebih berkuasa daripada dokter tersebut sama sekali tidak menganggapnya ketika dokter itu menegurnya. Terlebih lagi kepala perawat itu memperkaya dirinya dengan mengenakan pajak kepada semua pasien dan menjual obat kepada mereka. Perhatikan kutipan berikut: 
Dia berani memberi diagnosa, dan menempatkan si sakit di tempat yang diinginkannya. Aku perhatikan dia menyalami beberapa orang lebih dari sekali. Dia menerima, seperti dikatakan orang, "uang pelicin". Sementara itu, orang-orang yang seperti aku, yang tidak mengerti apa yang harus dilakukan, menunggu di lorong yang kotor dan berangin (Jelloun, 2010:34).

Pada kutipan di atas digambarkan bahwa kekuasaan tidak berdasarkan pada jabatan yang dimiliki seseorang, melainkan pada seberapa banyak uang yang didapatkan. Masalah ekonomi menimbulkan adanya sistem kapitalis seperti yang dilakukan oleh kepala perawat tersebut. Dia mengenakan pajak kepada semua pasien dan dia memberikan obat-obatan kepada mereka. Selain itu, dia mendapatkan komisi dari klinik-klinik swasta ketika dia mengirimkan mereka ke sana. Dalam suatu sistem di rumah sakit yang berhak mendiagnosa, memberikan resep obat, dan memberikan rujukan klinik adalah dokter bukan perawat.

\section{Kemerosotan Moral}

Menurut Murad, Haji Hamid mempunyai kehidupan ganda. Dia baik hati kepada istrinya, namun di luar itu, dia mengadakan pesta orgi di sebuah apartemen yang dia sewa bersama temannya. Perhatikan kutipan berikut:

Hamid mempunyai kehidupan ganda. Aku tahu. Kukira istrinya pun tahu. Dia menghujaninya dengan hadiah dan uang. Dia membeli permata. Dia yang mengatakannya kepadaku pada suatu hari. Istrinya memiliki dua sabuk emas. Baginya itu investasi meskipun harga emas tak banyak bergerak. Dia menyewah apartemaen dengan temannya yang sama busuknya dengan dia, namanya Taibi, Haji seorang ahli dalam pembelian barang-barang untuk kementrian. Gadis-gadis diambilnya ketika baru keluar dari sekolah menengah atau kadang-kadang di kampus universitas. Kehidupan tersenyum kepada mereka. Gadis-gadis berjatuhan seperti lalat. Kadang-kadang mereka mengadakan pesta orgi (Jelloun, 2010:127-128). 
Kutipan di atas menggambarkan tentang kehidupan koruptor yang mempunyai kehidupan ganda. Pada satu kehidupannya dia baik terhadap istrinya, namun pada kehidupannya yang lain dia menghilangkan moralnya. Kutipan "mereka mengadakan pesta orgi" merupakan salah satu ciri kehidupan koruptor, mereka menikmati hidup dari hasil yang tidak baik dan membawa gadis-gadis, kemudian mereka berpesta orgi di studio yang mereka sewa. Pada kutipan tersebut terdapat kemerosotan moral yang dialami oleh Haji Hamid dan Taïbi.

\section{Hegemoni Kekuasaan (Kelas Sosial)}

Subaltern menurut Gayatri Spivak adalah kelompok-kelompok yang mengalami penindasan oleh kelas penguasa, eksploitasi terhadap kaum tertindas yang disebabkan adanya dominasi struktural. Dengan kata lain, kaum subaltern tidak memiliki ruang untuk menyuarakan aspirasinya. Kaitan dengan konteks novel Korupsi, korupsi merupakan produk dari sikap hidup satu kelompok masyarakat yang memakai uang sebagai standar kebenaran dan sebagai kekuasaan mutlak. Akibatnya, kaum koruptor yang kaya raya dan para politisi korup yang berkelebihan uang bisa masuk ke dalam golongan elit yang berkuasa dan sangat dihormati. Sehingga masyarakat yang biasa tidak dapat melakukan sesuatu. Hal tersebut dapat dilihat pada kutipan di bawah ini:

Haji Hamid masuk dan meletakkan berkas Tuan Sabbane di mejaku sambil berkata, seakan-akan aku ini bawahannya, bahwa aku harus mengurus masalah itu secepatnya. Kubuka berkas itu. Kupelajari rencana dan proyeknya (Jelloun, 2010:67)

Pada kutipan seolah-olah aku adalah bawahannya, bahwa aku harus mengurus masalah itu dengan cepat terdapat subaltern yang dialami Murad. 
Murad mengalami penindasan oleh asistennya, Haji Hamid dikarenakan adanya dominasi struktural di kantornya.

\section{Marginalitas}

Pada umumnya marginalitas diartikan sebagai orang-orang yang tergolong ke dalam kelompok terpinggirkan atau miskin. Cakupan kelompok terpinggirkan atau marginal adalah orang-orang yang mengalami satu atau lebih dimensi penyingkiran diskriminasi, atau eksploitasi di dalam kehidupan sosial, ekonomi, dan politik kota. Data-data di bawah ini merupakan analisis marginalitas yang terdapat dalam novel. Keadaan ekonomi Murad yang memprihatinkan membuatnya diperlakukan tidak baik oleh ibu mertuanya. Hal tersebut dapat dilihat pada kutipan di bawah ini:

Hanya aku yang tidak diperlakukannya semena-mena, aku merusak pemandangannya. Aku adalah kesalahannya. Orang yang seharusnya tidak masuk ke dalam keluarga itu (Jelloun, 2010:24-25).

Pada kutipan "Hanya aku yang tidak diperlakukannya semena-mena, aku merusak pemandangannya” terdapat diskriminasi ekonomi yang dialami Murad. Keterbatasan pendapatan untuk memenuhi kebutuhan sehari-harinya menjadikannya sebagai orang miskin di keluarga istrinya dan itulah yang menyebabkannya menjadi korban marginal. Diskriminasi yang dilakukan oleh ibu mertuanya dikarenakan adanya rasa egoisme dan rasa kecenderungan mengunggulkan menantu yang satu dan yang lainnya, contohnya antara Murad dan Sidi Larbi. 
Orang-orang kaya adalah orang-orang yang berkuasa. Mereka selalu merendahkan orang-orang yang lemah. Hubungan antara Hilma dan Murad menjadi memburuk karena adanya tekanan dari keluarga Hilma. Selain itu, keadaan ekonomi juga mendorongnya untuk protes menginginkan kehidupan yang lebih baik. Perhatikan kutipan berikut:

... Hilma bisa hidup damai dengan suaminya yang sederhana, tapi dia berada di bawah pengaruh keluarganya dan memaksanya untuk protes. Ayahnya tidak mengatakan apa-apa. Dia menghargai Mourad, mengetahui keseriusannya dan kejujurannya. Ibunya orang yang munafik. Dia tersenyum lebar kepada Mourad, tetapi dibelakangnya dia mengejeknya (Jelloun, 2010:22-23).

Pada data tersebut dijelaskan bahwa adanya dominasi kekuasaan, yaitu dominasi ekonomi yang dilakukan ibu mertuanya terhadap Murad. Dominasi tersebut dikarenakan keadaan ekonomi Murad dan Hilma yang tidak sesuai dengan harapan ibunya dan ibunya adalah orang yang munafik. Dominasi ekonomi menimbulkan penggolongan orang-orang terhadap tingkat kelas orang tersebut. Itulah yang dilakukan ibu mertuanya. Dia mengeluarkan senyumnya di depan Murad, namun di belakang dia menghina Murad karena status ekonominya. Hegemoni ekonomi yang terjadi pada ibu mertua Murad dikarenakan ibu mertuanya adalah orang yang materialistis. Orang-orang jujur yang berada di tengah-tengah masyarakat korup mengalami pembatasan dalam pergerakannya. Itulah yang dialami oleh Murad dan orang-orang seperti dirinya. Perhatikan kutipan di bawah:

Aku tidak tahu kenapa, tapi orang-orang sepertiku terhukum untuk berjalan di dalam terowongan. Aku tidak memiliki jalan keluar lagi. Bila aku mengambil suatu jalan, maka jalan itu akan berubah menjadi terowongan dan sering kali di ujungnya ada sebuah sumur (Jelloun, 2010:52). 
Pada kutipan di atas terdapat marginalitas yang dialami oleh orang-orang jujur. Mereka mengalami penyingkiran dalam kehidupan sosial. Pergerakan mereka dibatasi, mereka seolah-olah dilarang untuk memperluas ruang geraknya. Jika mereka ingin keluar dari penyingkiran tersebut, maka mereka harus rela untuk masuk kedalam kelompok yang tidak sesuai dengan ideologi mereka. Hal itu tergambarkan pada kutipan Aku tidak tahu kenapa, tapi orang-orang sepertiku terhukum untuk berjalan di dalam terowongan.

\title{
8. Resistensi
}

Murad pernah menyesali uang yang diberikan padanya oleh seorang kontraktor bangunan ketika mereka berada di sebuah restoran di Casablanca. Namun Murad tidak ingin melanggar prinsipnya dan bertindak kotor seperti teman-temannya. Perhatikan kutipan berikut:

\begin{abstract}
Murad siap mengorbankan semuanya tapi tidak melanggar semua prinsipnya dan bertindak seperti yang lainnya. Meskipun begitu, kadang-kadang dalam waktu sekejap, dia menyesali seberkas lembaran uang yang pernah diberikan seorang kontraktor bangunan, Pak Foulane, untuknya di atas meja sebuah kafe di kota itu. Pasti jumlahnya ada satu juta.Dengan satu juta, dia bisa membeli sepeda motor, gaun untuk Hlima, dan pakaian pesta untuk anak-anaknya. Mereka semua bisa pergi makan ikan di restoran, dia bisa menghisap rokok Amerika dan mungkin dia bisa membeli untuk dirinya sendiri cerutu Monte Cristo No. 1 spesial seharga delapan puluh dirham, dua kali biaya makannya sehari-hari. Dia cukup tanda tangan, sebuah tanda tangan kecil di bagian bawah kertas.Tidak, dia tidak bisa dibeli. Dia berdiri dan meninggalkan kafe, sangat marah. ...(Jelloun, 2010:21-22).
\end{abstract}

Pada kutipan "Tidak, dia tidak bisa dibeli. Dia berdiri dan meninggalkan kafe, sangat marah" sebuah penolakan yang dilakukan oleh Murad kepada Pak Foulane sebagai seorang kontraktor bangunan. Pak Foulane yang ingin mengajukan permohonan pendirian bangunan di Casablanca sehingga ia ingin 
memberikan sejumlah uang agar pendirian bangunan dapat segera dilaksanakan tanpa melalui proses birokrasi yang seharusnya. Dengan kata lain, yang dilakukan oleh Pak Foulane adalah ingin menyuap Murad. Namun Murad tetap pada pendiriannya bahwa dia tidak bisa melakukan hal tersebut karena itu melanggar prinsipnya. Murad sangat menghargai prinsipnya, yaitu dia tidak bisa disuap.

\section{KESIMPULAN}

Peneliti melakukan analisis novel berdasarkan kajian sosiologi sastra dan teori hegemoni. Dalam teori hegemoni terdapat bentuk-bentuk penyalahgunaan kekuasaan yang menjadi pokok bahasan dalam menganalisis novel Korupsi, yaitu:

1. Hegemoni yang terjadi pada masyarakat atas meliputi: a) Penggelapan uang, b) Penyuapan, c) Korupsi, d) Pemerasan.

2. Kemerosotan Moral

3. Hegemoni (kekuasaan) Kelas Sosial

4. Marginalitas

5. Resistensi

Berdasarkan hasil analisis dan pembahasan mengenai hegemoni dalam novel Korupsi karya Tahar Ben Jelloun, dapat ditarik beberapa simpulan sebagai berikut:

a. Hegemoni yang terjadi pada novel ini tidak hanya sebatas dominasi kekuasaan suatu kelas sosial, tetapi juga terjadi atas kesadaran untuk melakukan perubahan. Seperti yang terjadi pada Murad untuk mengubah keadaan ekonomi keluarganya. 
b. Hegemoni kekuasaan yang terjadi pada novel ini adalah Kaum subaltern pada novel ini adalah Murad yang tidak mempunyai suara untuk menyatakan keberatannya terhadap apa yang dilakukan oleh Haji Hamid.

c. Hegemoni moral merupakan sikap untuk melindungi diri. Hegemoni moral dalam novel ini tergambarkan pada tokoh Murad, ibu mertua Murad, dan Haji Hamid yang berpura-pura untuk menyukai sesuatu agar hidupnya tidak terancam dan tidak masuk ke dalam golongan orang yang termarginalkan.

d. Marginalitas yang ada pada novel ini yaitu diskriminasi itu terjadi karena perbedaan status sosial, ekonomi, faktor kejujuran pada diri Murad, pelajar dari kalangan bawah, orang-orang miskin lainnya, dan juga di lingkungan tempat tinggal orang-orang marginal.

e. Resistensi muncul karena adanya kebebasan yang tidak terpenuhi. Seseorang akan bersifat resisten sebagai langkah terakhir untuk memenuhi kebebasannya.

\section{E. DAFTAR PUSTAKA}

Jelloun, Tahar Ben. 2010. Korupsi. Jakarta: Serambi Ilmu Semesta

Kosasih. 2012. Dasar-Dasar Ketrampilan Bersastra. Bandung: Yrama Widya

Moleong. 2012. Metodologi Penelitian Kualitatif. Bandung: Remaja Rosdakarya.

Wicaksono. 2013. Pengembangan Sistem Pendidikan di Indonesia. Bandung: Pustaka Setia. 
Penyalagunaan Kekuasaan Dalam Novel Korupsi Karya Tahar Ben Jelloun (kajian Sosiologi Sastra) 